\title{
Performance Analysis of Solar Water Heater
}

\author{
Shahidul Islam Khan, Asif Islam* \\ Department of Electrical \& Electronic Engineering, Bangladesh University of Engineering \& Technology, Dhaka, Bangladesh. \\ Email: shahidul@eee.buet.ac.bd, ${ }^{*}$ asif038@gmail.com
}

Received May 30 ${ }^{\text {th }}$, 2011; revised June 21 ${ }^{\text {st }}$, 2011; accepted June $28^{\text {th }}, 2011$.

\begin{abstract}
Two solar water heaters of 100 liter and 200 liter were installed on the roof-top of electronics laboratory at Old Academic Building $(O A B)$ of Electrical and Electronics Engineering Department of BUET. The data of 12 months have been collected and analyzed in this paper. It is found that the incoming hot tap water is about $30^{\circ} \mathrm{C}$ higher than the room temperature during day time during winter months. This is about $25^{\circ} \mathrm{C}$ in afternoon hours.
\end{abstract}

Keywords: Solar Irradiation, Solar Water Heater, Thermosyphon

\section{Introduction}

Greatest amount of solar energy is available in two broad bands [1] encircling the earth between $15^{\circ}$ and $35^{\circ}$ latitude north and south. The next best position is the equatorial belt between $15^{\circ} \mathrm{N}$ and $15^{\circ} \mathrm{S}$ latitude [2]. Most of the developing countries, being situated in [3] these regions, are in a favorable position in respect of solar energy. Bangladesh is situated between $20.34^{\circ}$ and $26.38^{\circ}$ latitude [4] north and as such has a good solar energy potential. Average daily solar irradiation [5] at flat surface is around 4.0 to $6.5 \mathrm{kWh} / \mathrm{m}^{2}$ in Bangladesh (Figure 1). Solar water heaters are used all over the world $[6,7]$ specifically in sunny countries where sun-shine is abundant. The hot water is used for household purpose and in restaurants, hospitals, dormitories, etc. for cleaning dishes and other works. These heaters are also used for preheating water for industrial purpose. In Bangladesh, solar water heaters are getting popular slowly. There are a few companies who are selling these heaters. Most of the water heaters are of Chinese origin and some are of Indian origin. Unlike Nepal, water heaters are not that popular as gas heaters are cheaper in our country. As the water heaters are installed for 13 months on OAB building so data of 1 year (12 months) have been collected and analyzed. However, the data collected in the winter time contains some useful information.

\section{Application of Solar Energy}

Most of the solar energy applications [8] are concerned with trapping sunlight as photovoltaic (PV) heat. Because of the low energy density of sunlight, the higher the temperature needed the more complicated and expen- sive [9] the system will be. Depending on the range of temperature use, solar thermal applications [10] are divided into the three broad categories:

1) Low-temperature applications (below $100^{\circ} \mathrm{C}$ ), such as solar drying, hot water supplies, cooking.

2) Medium-temperature applications (below $150^{\circ} \mathrm{C}$ ), such as refrigeration, industrial process heat, etc.

3) High-temperature (above $150^{\circ} \mathrm{C}$ ) applications, such as electricity generation

\section{Solar Water Heater}

As In any collection device, the principle usually followed is to expose a dark surface to solar radiation so that the radiation is absorbed. A part of the absorbed radiation is then transferred to a fluid like air or water. When no optical concentration is done, the device in which the collection is achieved is called a flat-plate collector.

The flat-plate collector is the most important type of solar collector because it is simple in design, has no moving parts and requires little maintenance. It can be used for a variety of applications in which temperatures ranging from $40^{\circ} \mathrm{C}$ to about $100^{\circ} \mathrm{C}$ are required.

\section{Thermosyphone}

The principle of thermosyphone [11] is just like boiling the water. In a flat bed collector cold water flows to the collector, it gets warm by sunshine and flows upward due to buoyancy and stored in the tank which can be used directly.

A collector essentially consists of the following components:

1) A coated flat plate which absorbs solar radiation 


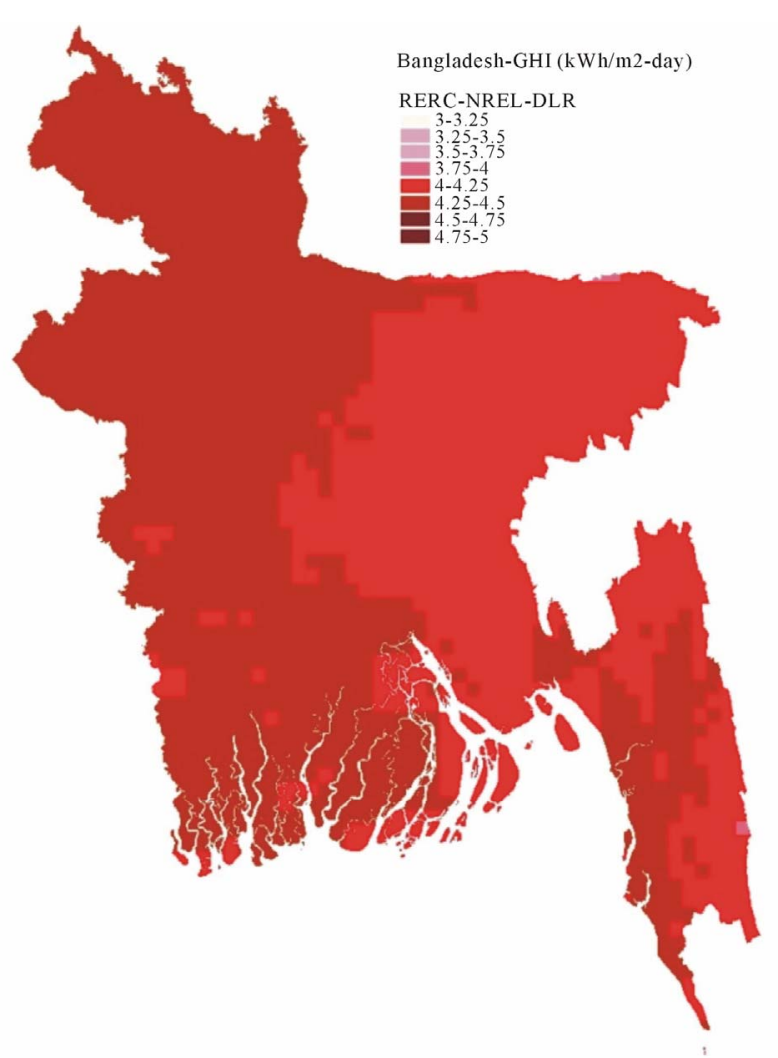

Figure 1. Solar irradiation map (Source: SWERA, UNEP/ GEF).

and transforms it into thermal energy

2) An insulated storage tank used to reduce thermal losses of heated water glass or plastic

3) Cover to reduce upward thermal losses of the collector

4) Bottom insulation to reduce downward thermal losses

5) Tubes and channels for circulating water to collect thermal energy

6) Wooden or metallic frame to house the collector assembly

Solar water heater is basically a flat-plate [9] collector in which heat transfer fluid is water. In Figure 2, the working principle of solar water heater has been shown.

\section{Data Analysis}

The reading collection of the room \& tap water temperature of 100 Liter and 200 Liter solar water heater was started from November 1, 2008. As Thursday and Friday are the weekly holidays at BUET, no data could be taken at those days. Data has been collected up-to October 31, 2009. So a full cycle data of complete one year has been collected successively.

There was some drop in temperature as the pipes were

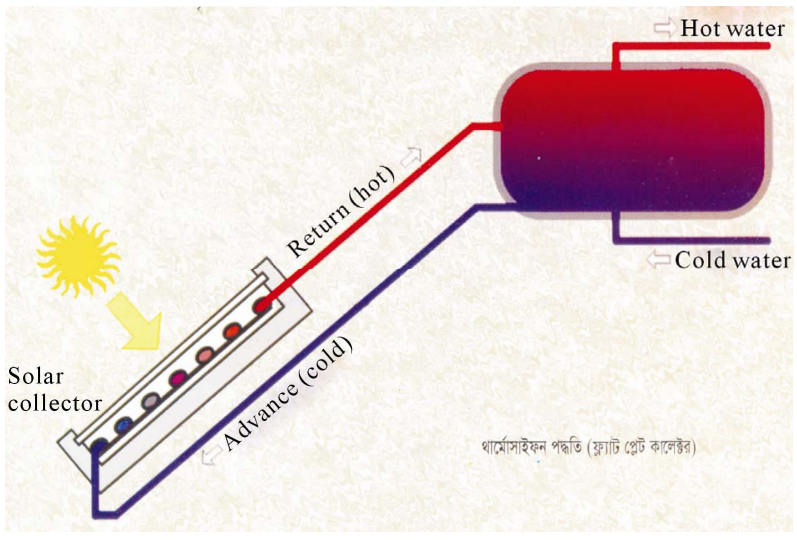

Figure 2. Thermosyphone principle of solar water heater (Source: LGED).

long between water heater tank and the tap in the wash basin. Moreover, 200 Liter pipes are not insulated. Although 100 Liter heater piping was insulated but rats and birds destroyed it in two weeks after installation. So there is also loss of temperature in 200 Liter heater. A solution could be to paint the piping with black color. The temperature retaining capability of 200 liter heater is better (Figure 3 \& Figure 4) than 100 liter heater.

Temperature variation in the curve is due to foggy days during winter months in November and December. The comfortable temperature during winter month for household purpose is about $32^{\circ} \mathrm{C}-4^{\circ} \mathrm{C}$, which can easily be attained.

\section{Conclusions}

It is found from the data that the solar water heaters are working without disturbance. The tap water temperature is about $25^{\circ} \mathrm{C}$ to $30^{\circ} \mathrm{C}$ higher than room temperature during day time. It is expected that during evening hours it should be around $20^{\circ} \mathrm{C}$ higher than room temperature. This hot tap water when mixed with cold tap water can be used comfortable according to comfort level of the user. Data for one year has been collected to analyze fully the

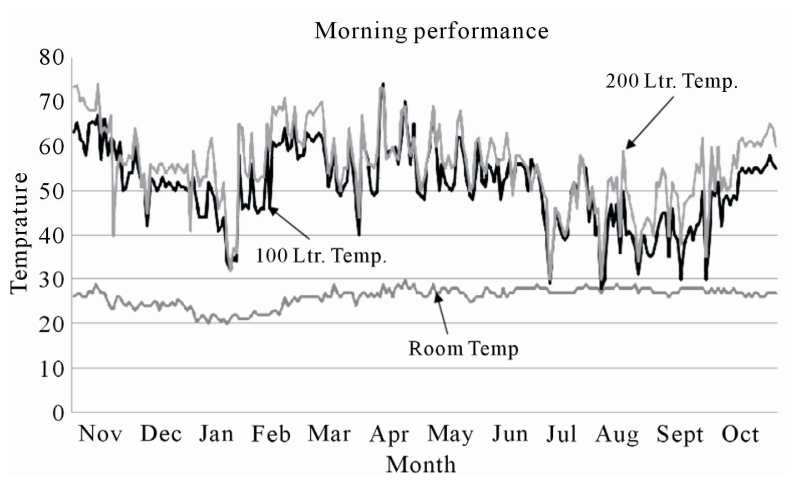

Figure 3. Solar water heater performance (morning). 


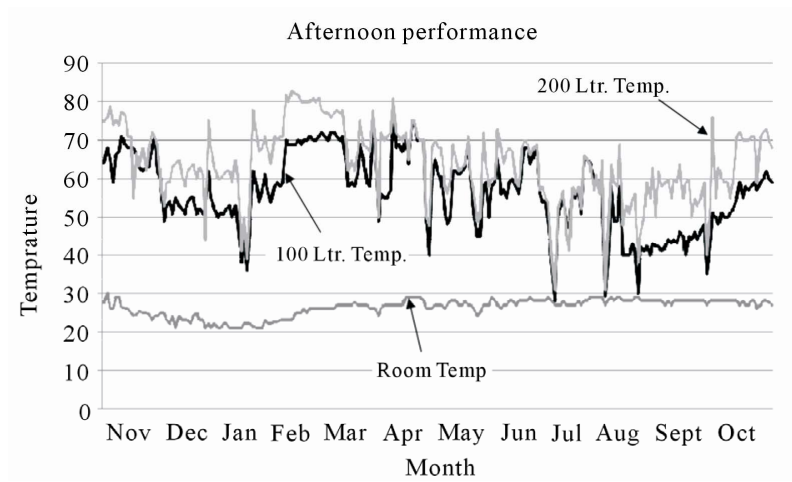

Figure 4. Solar water heater performance (afternoon).

performance of the solar water heaters over the whole year.

\section{Acknowledgements}

The authors would like to thank the Centere for Energy Studies, Bangladesh University of Engineering \& Technology (BUET) for technical and data support.

\section{REFERENCES}

[1] J. A. Duffie, "Solar Engineering of Thermal Processes," John Wiley \& Sons, New york, 1980.

[2] S. Rahman, S. H. Sarker and S. Huque "Performance Study of an Indigenously Built Flat Plate Solar Water Heater," Proceeding ICDRET First International Conference on the Developments in Renewable Energy Technology, Dhaka, 2009, pp. 1-4.

[3] F. Kreith and J. F. Kreider, "Principles of Solar Engineer- ing,” Hemisphere Publishing, New York, 1978, p. 17.

[4] "Regional Environmental Information Network," http://www.rein.org/solar/resources/index.html.

[5] M. A. Baten, B. S. Nahar, R. Khatun and M. B. Khan, "Observation of Micrometeorological Parameters Over Harvested Rice Field in 2004," Bangladesh Journal of Environment Science, Vol. 12, No. 1, 2006, pp. 52-55.

[6] R. Diekmann, "Solar and Wind Energy," International Issue 5, Bielefelder Verlag GmbH \& Co., Bielefeld, 2008.

[7] J. Jimenez-Gonzalez and A. A. Irizarry-Rivera, "Generation Displacement, Power Losses and Emissions Reduction Due to Solar Thermal Water Heaters,” Proceeding IEEE $37^{\text {th }}$ Annual North American Power Symposium, Ames, 23-25 October 2005, pp. 617-621

[8] Y. G. Yin, "Design and Application of Solar Water Heater Intelligent Control System,” Proceeding ICEET International Conference on Energy and Environment Technology, Guilin, Vol. 1, 2009, pp. 580-583, doi:10.1109/ICEET.2009.147.

[9] D. Mengda, Z. Ying, L. Jian, X. H. Ma and Y. T. Wang "Design and Application of Solar Water Heater Intelligent Control System,” Proceeding ICEET International Conference on Energy and Environment Technology, Vol. 1, 2009, pp. 580-583. doi:10.1109/ICEET.2009.147.

[10] A. Cellatoglu and K. Balasubramanian "Renewable Energy Resourses for Residential Applications in Coastal Arears: A Modular Approach,” Proceeding SSST 42 ${ }^{\text {nd }}$ Southestern Sysposium on System Theory, Tyler, 2010, pp. 340-345. doi:10.1109/SSST.2010. 5442813

[11] S. I. Khan and M. Obaidullah, "Fundamentals of Solar Water Heaters," Short Course on Energy Efficiency, Bangladesh University of Engineering \& Technology, Dhaka, November 2008, pp. 20-29. 